\title{
Acute and Chronic Toxicity of Thioacteamide and Alterations in Blood Cell Indices in Rats
}

\author{
Muddasir Hassan Abbasi ${ }^{1,2}$, Tasleem Akhtar ${ }^{1}$, Ihtzaz A. Malik ${ }^{3,4}$, Sana Fatima ${ }^{3}$, Babar Khawar ${ }^{2}$, \\ Khawaja Abdul Mujeeb ${ }^{2}$, Ghulam Mustafa ${ }^{1}$, Shabir Hussain ${ }^{3}$, Javaid Iqbal ${ }^{5}$, Nadeem Sheikh ${ }^{2 *}$
}

${ }^{1}$ Department of Zoology, Government College of Science, Lahore, Pakistan; ${ }^{2}$ Cell and Molecular Biology Lab, Department of Zoology, University of the Punjab, Lahore, Pakistan; ${ }^{3}$ University of Health Sciences, Lahore, Pakistan; ${ }^{4}$ Department of Internal Medicine, University of Goettingen, Goettingen, Germany; ${ }^{5}$ Department of Anatomy Shaikh Zayed, Postgraduate Medical Institute, Shaikh Khalifa Bin Zayed Medical and Dental College, Lahore, Pakistan.

Email: muddygcs@gmail.com, tasleem_seerat@yahoo.com,ihtzaz_malik@yahoo.de,sf.koolsun21@gmail.com, babarkhawar@yahoo.com,mujeeb.khawaja@gmail.com,gm.gcs271@gmail.com, ashas740@yahoo.com, drjsyed@hotmail.com, ’s_nadeem77@yahoo.com

Received November $18^{\text {th }}$, 2012; revised December 20 ${ }^{\text {th }}$ 2012; accepted December $28^{\text {th }}, 2012$

\begin{abstract}
Background: Thioacetamide (TAA) has been used extensively in the development of suitable animal models of acute and chronic liver injury employing various doses, times and routes of its administration, particularly in drinking water due to its resemblance with human liver fibrosis and cirrhosis. The aim of this study was to investigate and compare hematological alteration during the acute and chronic liver inflammation. Methods: Acute Liver inflammation was induced in Wistar rats via intraperitoneal injection of thioacetamide and the animals were sacrificed $12 \mathrm{~h}$ after the TAA administration. Induction of chronic liver inflammation was performed by continuous administration of TAA in the drinking water $(200 \mathrm{mg} / \mathrm{L})$ during 18 weeks of experiment. After that all animals were sacrificed and Blood samples were collected for further analysis. Results: Single intra peritoneal injection of TAA (300 mg/kg B.W.) induced an acute condition with hematological changes including leukocytosis with marked neutrophilia $(\mathrm{P}=0.0429)$, lymphopenia, thrombocytosis as well as increased hemoglobin concentration $(\mathrm{P}<0.05)$ and decline of erythrocytic count $(\mathrm{P}=0.0009)$. Eighteen weeks of uninterrupted supply of TAA $(200 \mathrm{mg} / \mathrm{L})$ in drinking water lead to chronic inflammation and the hematological alterations were leucopenia $(\mathrm{P}=0.0197)$ accompanied with neutropenia and thrombocytopenia. Increase in RBCs $(\mathrm{P}=0.0073)$ and $\mathrm{Hb}$ contents was also observed with a decline of red cell indices. Conclusion: Taken together these findings we can conclude that the animals respond differently under acute and chronic inflammatory condition with TAA administration. Leukocytosis with marked neutrophilia, thrombocytosis as well as increased hemoglobin concentration and decline of erythrocytic count were observed in acute while leucopenia accompanied with neutropenia and thrombocytopenia and increase in RBCs, $\mathrm{Hb}$ and Hct was also observed with a decline of other red cell indices during chronic phase.
\end{abstract}

Keywords: Haematology; Inflammation; Leucocytosis; Leucopenia; Neutrophilia; Neutropenia; Thrombocytosis and Thrombocytopenia

\section{Introduction}

Thioacetamide (TAA), a potent hepatotoxin, was first used to control the decay of citrus fruits especially oranges and then as a fungicide. Various industrial as well as pharmaceutical applications, TAA acts as sulfur donor. Later it was found that it serves as a potent chemical carcinogen [1-4].

TAA induced inflammation leads to cirrhotic conditions in the rat liver that resembles the human alcoholic liver fibrosis. It is a model hepatotoxicant and responsi-

\footnotetext{
"Corresponding author.
}

ble of severe damage to the cells with significant toxic effects on biosynthesis of macromolecules including proteins and nucleic acids [5]. The injury to the liver cell population is due to increased production of TAA metabolites including sulfines and sulfene [6,7]. It has been reported that TAA can also injure different organ systems besides liver, including lungs, intestine, kidneys, spleen, thymus and pancreas [8-13].

TAA is bio-transformed or metabolized by flavincontaining monooxygenase (FMOs) systems [14] and cytochrome P450 (Cyt-p450) [4]. FMOs and Cyt-p450 reduce dioxygen to superoxide anion, which is catalyzed 
to form hydrogen peroxide [15]. Enzymes of Cyt-p450 are present in the liver microsomes, which converts TAA to a toxic reactive intermediate called thioacetamide Soxide (TASO) \& due to oxidation process it induces oxidative stress in the hepatic cells that finally leads to centrilobular necrosis and liver injury [1,16-19]. It also provokes a remarkable increase in the size of the nucleoli, as well as in the amount and activity of total mRNA of liver cells [20].

TAA has been extensively used for several years to establish a model of acute \& chronic liver injury in rats, mice and other animals [21-23], utilizing its various doses (50 - $600 \mathrm{mg} / \mathrm{Kg} \mathrm{B.W.)} \mathrm{and} \mathrm{routes} \mathrm{of} \mathrm{administra-}$ tion [24-28] particularly in drinking water [29-32] and in the diet [17] because of the fact that the clinical conditions, biochemical and histological alterations in TAAinduced models have shown high similarity to human liver failure [33-41].

Acute toxic effect of TAA is dose dependent as single dose leads to injury specified to centrilobular region of the liver with subsequent regenerative response [33,41, 42]. Long-term thioacetamide administration is also an established technique for generating rat models of liver fibrosis and cirrhosis [15]. Prolonged oral intake of this chemical exhibited an external appearance of cirrhosis characterized by the presence of; numerous macro liver nodules, cell adenomas, cholangiomas and hepatocarcinoma, histologically similar to that caused due to viral hepatitis infection [20,43,44].

Little is known regarding changes in the blood cell indices during acute or chronic inflammation induced by TAA. Therefore, the aim of the current work was to compare hematological alterations of acute and chronic experimental inflammation using TAA as a model hepatotoxicant.

\section{Materials and Methods}

\subsection{Animals}

Healthy Wistar rats (about 300 g B.W.) were arranged from the Department of Zoology, GCS (Lahore-Pakistan), housed in wire-bottomed cages in an animal room under standard conditions with 12-h light/dark cycles and at an ambient temperature of $22^{\circ} \mathrm{C} \pm 1^{\circ} \mathrm{C}$, with fresh water and food pellets available ad libitum. All the animals were acclimatized under standard laboratory condition for a period of 2 weeks before the commencement of the experiment.

\subsection{Acute Inflammation}

Acute Liver inflammation was induced in Wistar rats via intraperitoneal injection of thioacetamide (Sigma Aldrich chemie, Switzerland; $300 \mathrm{mg} / \mathrm{kg}$ of B.W.), however, the control rats received injections of normal saline $(n=3)$. The animals were sacrificed $12 \mathrm{~h}$ after the TAA administration.

\subsection{Chronic Inflammation}

Induction of chronic liver inflammation was performed by continuous administration of TAA in the drinking water $(200 \mathrm{mg} / \mathrm{L})$ during 18 weeks of experiment whereas the control group received tap water.

All the animals were anesthetized with intra-peritoneal injection of ketamine-distilled water mixture (1:1), (50 $\mathrm{mg} / \mathrm{ml}$ of ketamine) and scarified. Blood of the control and treated animals, was drawn through direct cardiac puncture and processed for the measurement of blood cell indices.

\subsection{Assessment of Hematological Parameters}

Complete blood counts were performed on the samples of control and treated animals, using an automated blood cell analyzer Sysmex XT-1800i (Japan). It utilizes the technology of fluorescent flow cytometry and hydrodynamic focusing. Fluorescent technology consistently differentiates normal white blood cells (WBCs), Red blood cells (RBCs) and platelets (plts) from abnormal populations, thereby decreasing the number of manual interventions.

\subsection{Statistical Analysis}

The data were analyzed using Prism Graph pad 5 software (San Diego, CA). Statistical significance was calculated by two-sided t-test to assess differences against the control group. Significance was accepted at $\mathrm{P}<0.05$, $\mathrm{n}=3$.

\section{Results}

\subsection{Effect of Acute and Chronic Administration of TAA on Serum Level of Total and Differential Leukocyte Count}

A rise of $45 \%$ in Total Leukocyte count (TLC) compared to the respective control was observed in acute group (Figure 1(a)) while a similar percentage decline was noted in chronic group $(\mathrm{P}<0.05)$ (Figure 1(b)). Circulating level of subpopulation of WBCs was also analyzed. Neutrophils exhibited a marked statistical increase of $283 \%$ in acute group $(\mathrm{P}=0.0429)$ and decrease of $47.97 \%$ in chronic group $(\mathrm{P}=0.0391)$ (Figures 1(c) and (d)). The rest of the WBCs population in both of the studied groups showed no statistically significant change. Lymphocytes and monocytes showed a decrease of 20 and $94.25 \%$ compared to control during acute condition, while an increment of 34.60 and $9.52 \%$ was noted in the 
parameter during chronic condition. A general increase was also seen in eosinophils in both the experimental groups (Figures 1(e) and (f)).

\subsection{Assessment of Red Cell Indices and Platelets during Acute and Chronic Administration of TAA}

Blood level of platelets reflects an increment of $44 \%$ and decline of $6 \%$ in acute group and II, respectively compared to their respective controls (Figures 2(a) and (b)).

\section{Acute}

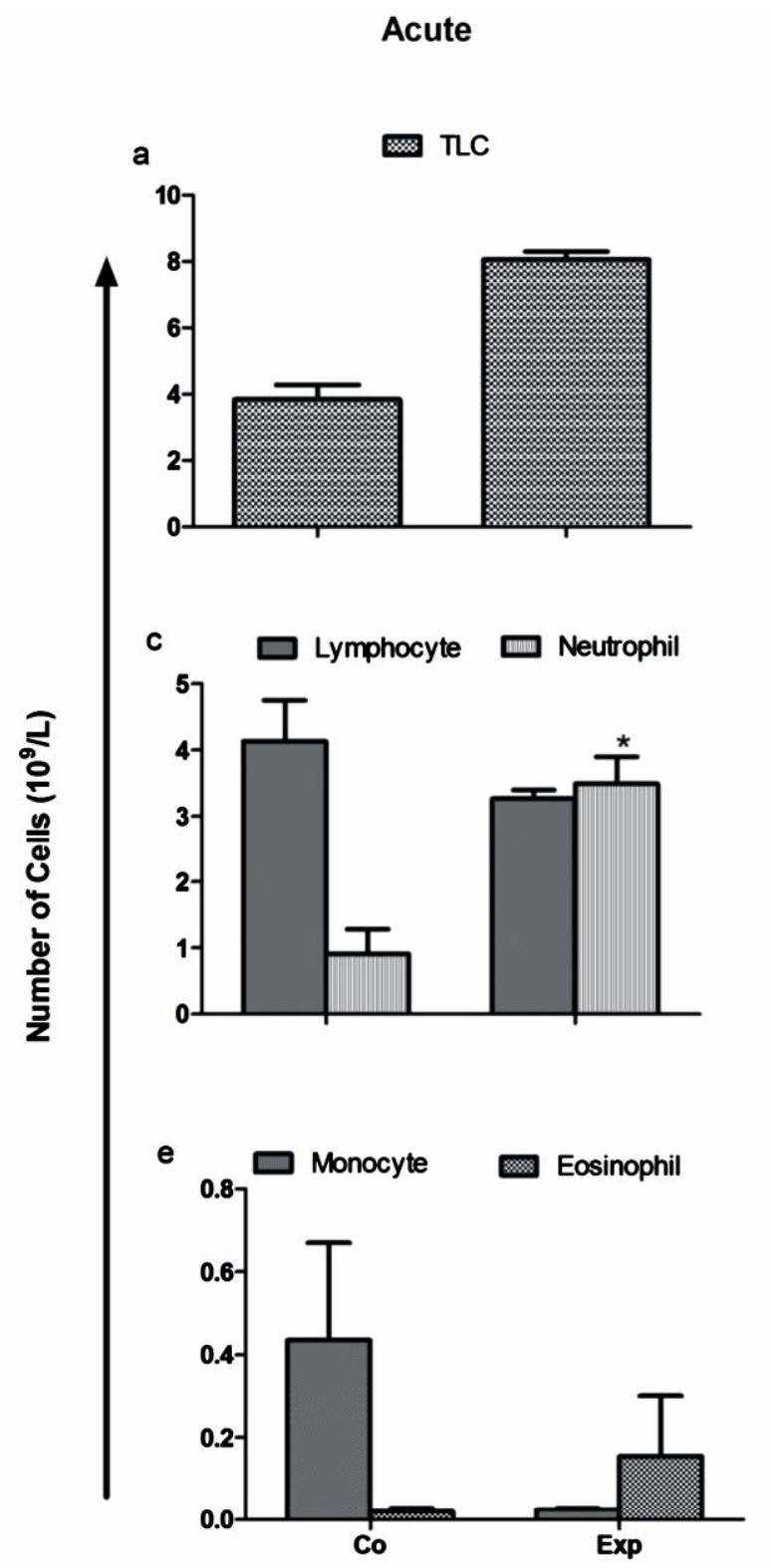

Mean cell volume (MCV), hematocrite (Hct), Mean cell haemoglobin concentration (MCHC) and Mean cell haemoglobin $(\mathrm{MCH})$ were studied. Except for Hct, all the other indices reflected an increasing trend in acute group while more or less a steady level with a minor decrease was observed in chronic group. Hct showed a statistically significant elevation in chronic group $(\mathrm{P}=$ 0.0001 ) while $27 \%$ decrease was noted between experimental and control samples in acute group $(\mathrm{P}<0.05)$ (Figures 3(a) and (b)).

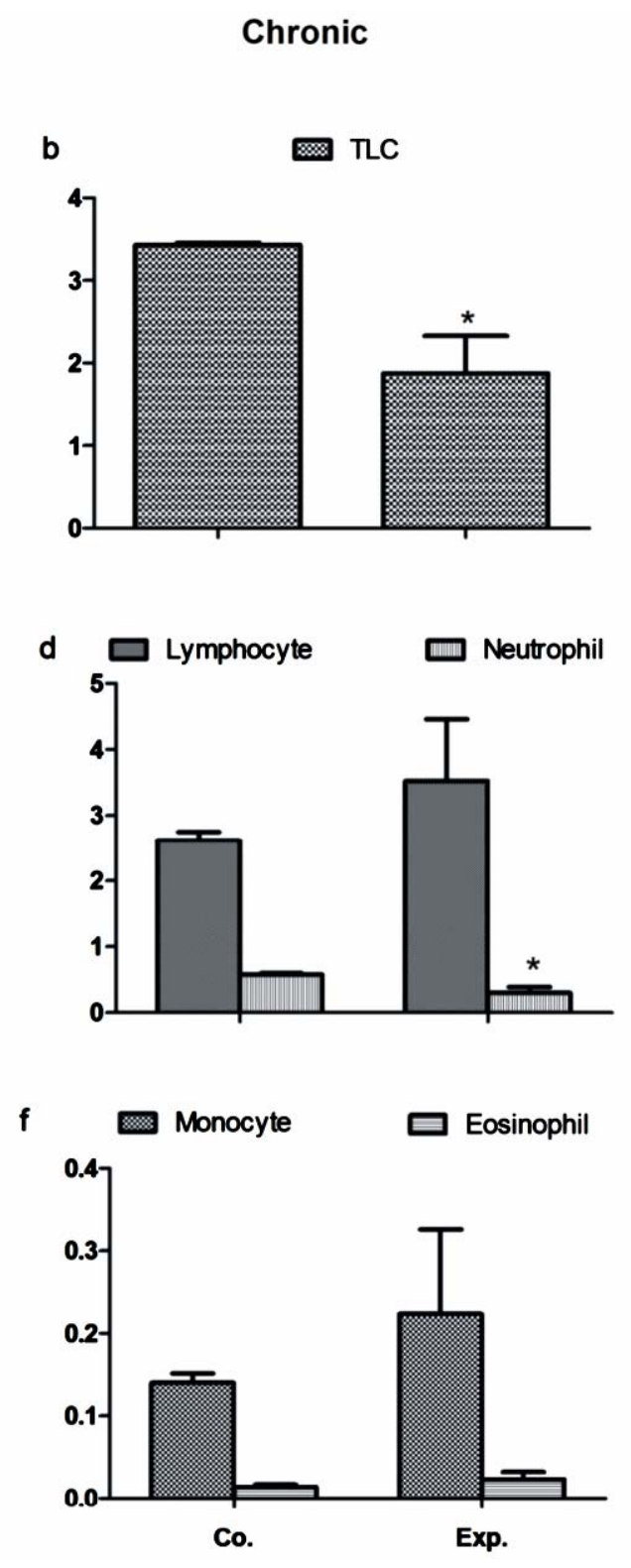

Figure 1. Total leukocyte count $\left(10^{9} / \mathrm{L}\right)$ in the treated animals as compared to control animals. A rise of $45 \%$ in TLC compared to the respective control was observed in acute group while a similar percentage decline was noted in chronic group (P $<0.05)$. Neutrophils exhibited a marked statistical increase of $283 \%$ in acute group $(P=0.0429)$ and decrease of $47.97 \%$ in chronic group $(P=\mathbf{0 . 0 3 9 1})$. The rest of the WBCs population in both of the studied groups showed no statistically significant change. 


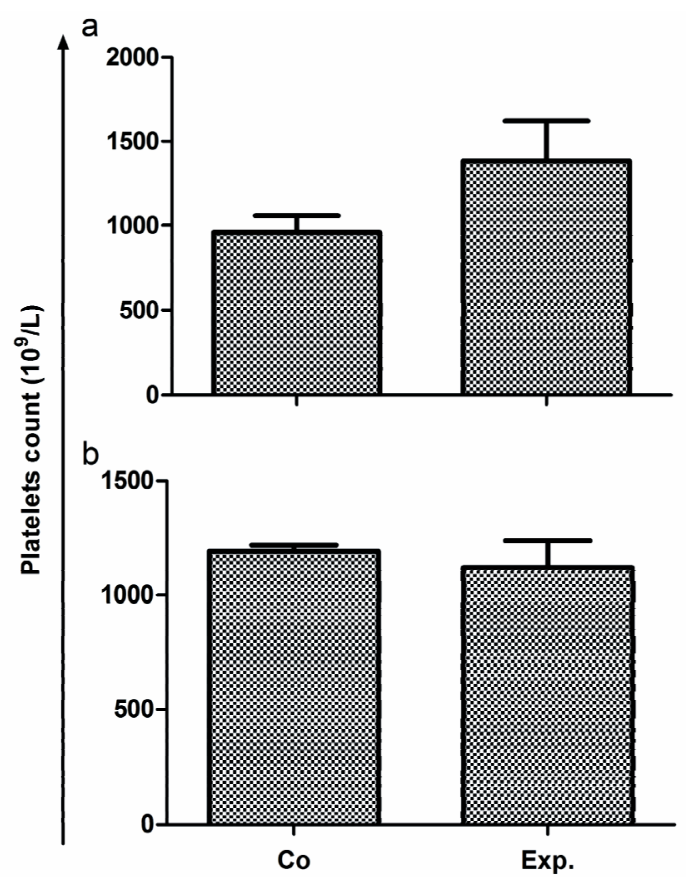

Figure 2. Platelets count $\left(10^{9} / \mathrm{L}\right)$ in the treated animals against control animals. Blood level of platelets reflects an increment of $44 \%$ and decline of $6 \%$ in acute group and chronic group, respectively compared to their respective controls.

Haemoglobin $(\mathrm{Hb})$ contents increased after TAA treatment in both groups. A statistical significant rise was observed in acute group $(\mathrm{P}<0.05)$ whilst minor increase of $4.1 \%$ was also noted in chronic group (Figures 3(c) and (d)). Regarding Red blood cells (RBCs), a significant decline was shown in acute group $(\mathrm{P}=0.0009)$ on the contrary to chronic group which showed a rise of $11 \%$ compared to the control $(\mathrm{P}=0.0073)$ (Figures 3(e) and (f)).

\section{Discussion}

Thioacetamide (TAA) administration either intraperitoneally or in drinking water up to 6 months produced liver cirrhosis and hepatic neoplasms in various animal models with significant biochemical and histological alterations, similar to those observed in human cirrhosis and it has been extensively investigated and reported in the scientific literatures [21-25,27,28,32-34,38,39].

In the present study, the hematological alterations of acute and chronic experimental inflammation in adult wistar rats were monitored because of their diagnostic significance. Intraperitoneal $(300 \mathrm{mg} / \mathrm{kg})$ acute group after $12 \mathrm{~h}$ and $(200 \mathrm{mg} / \mathrm{L})$ in drinking water up to 18 weeks, chronic group of TAA were shown to have dosedependent effects on blood profile of both of the animal groups.

The acute inflammation increased blood indices in- cluding $\mathrm{Hb}$, platelet levels, MCV, MCHC, MCH, TLC, neutrophils and decreased lymphocytes, monocytes, Hct and RBCs. On the contrary, during chronic phase, an increment was noted for RBC, Hct and Hb contents, remaining parameters have shown opposite results to that of acute inflammation.

Leukocytosis occurs in response to a wide variety of conditions, including viral, microbial infections, cancer, hemorrhage, and exposure to certain chemicals including steroids. The mechanism that causes leukocytosis includes: an increase, in number of leukocyte precursor cells in the bone marrow or their increased release from bone marrow storage pools, decreased margination of leukocytes into vessel walls and their decreased extravasation from the vessels into tissues [45]. Leukocytosis observed in case of acute group might be due to tissue necrosis or infarction resulted due to exposure of lethal dose of TAA. Decrease in RBCs count and $\mathrm{Hb}$ content leads to iron deficiency anemia which is characterized by a microcytic hypochromic blood picture $[46,47]$.

The depression in RBCs count and rise in $\mathrm{Hb}$ contents and red cell indices including MCV, MCHC, MCH, recorded in the present work in case of acute group is clear suggestive to a megaloblastic picture of RBCs and could be attributed to disturbed hematopoiesis, destruction of erythrocytes, and reduction in the rate of their formation and/or their enhanced removal from circulation. According to Travlos et al. (1996), consistent erythrocyte damage is presumed to be related to direct oxidative injury to the red cells by the chemicals or to the pitting function of the spleen. It may be assumed that the free radicals resulting from TAA metabolism caused liver injury [48].

Leucopenia is a clinical manifestation with decrease in circulating white blood cell (WBC) and is usually characterized by low granulocyte number, particularly the blood neutrophils. This notion is evident from the results observed in chronic group with a significant negative change of $47.97 \%$ in the level of the neutrophils and $6 \%$ of thrombocytes. These results could be attributed to a rare case of hematologic side effects called neutropenia and thrombocytopenia often associated with antipyretic drug overdose like paracetamol [49,50]. Hematological stem cells destruction due to underlying malignancies, acute and chronic disorders of alcohol abuse also causes thrombocytopenia [51,52]. Hypersplenism contribute to the thrombocytopenia if cirrhosis of the liver is present as well. Leucopenia and increased RBC and $\mathrm{Hb}$ contents were observed with the administration of $50 \mathrm{mg} / \mathrm{kg}$ of ciprofloxacin and pefloxacin in rats inflamed with formaldehyde [53]. Similar results were supported by Moura et al. [54] with the administration of $500 \mathrm{mg} / \mathrm{kg}$ of the leaf extract of Ageratum conyzoides in chronic (formaldehyde-induced arthritis) models of inflamed rats. Radiations, endogenous or exogenous chemicals and microbial 

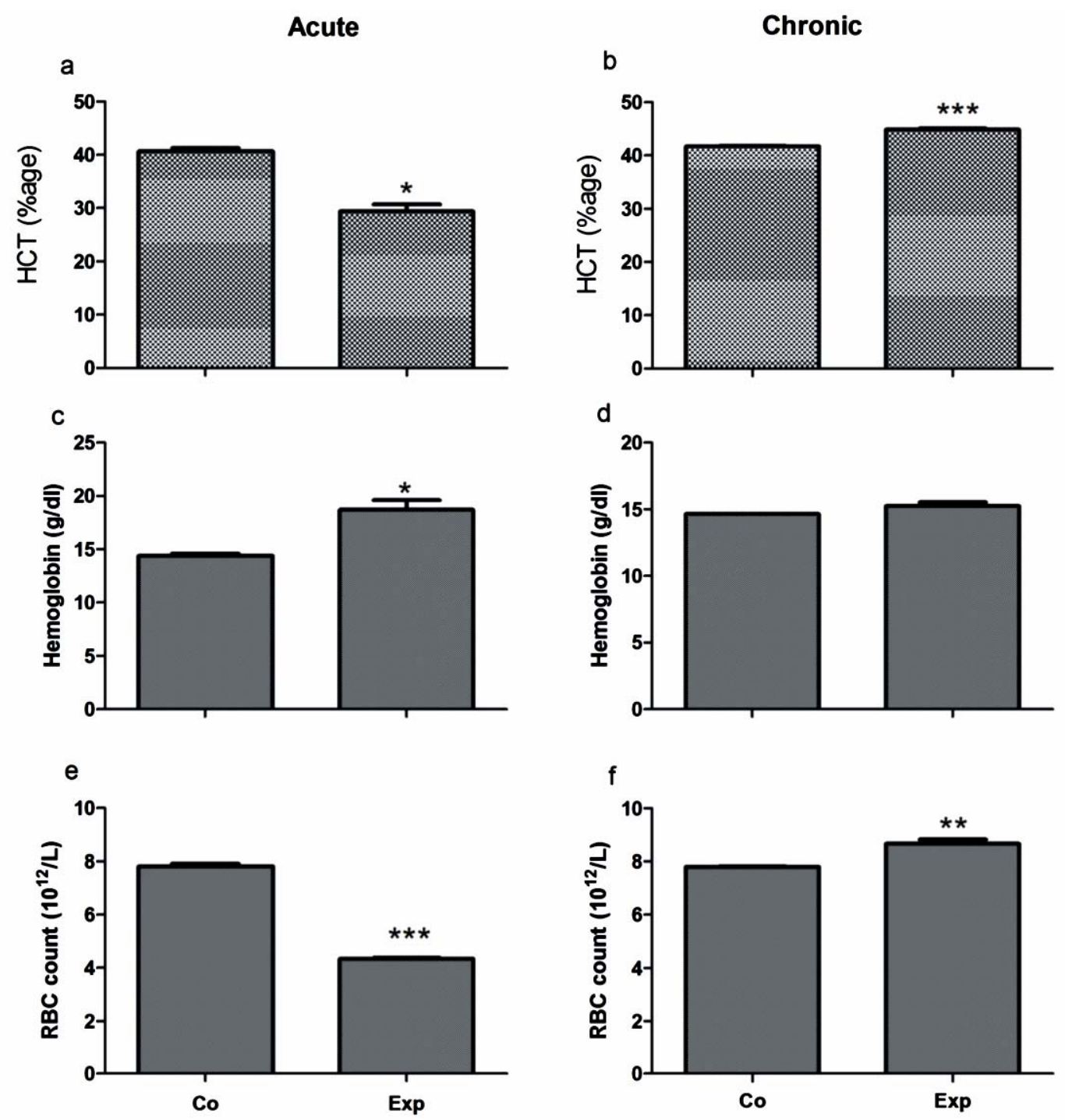

Figure 3. Estimation of hematological parametersin the treated animals against control animals.Hct showed a significant elevation in chronic group (P = 0.0001) while $27 \%$ decrease was noted in acute group $(P<0.05)$. A significant rise of $\mathrm{Hb}$ contents was observed in acute group $(P<0.05)$ whilst minor increase of $4.1 \%$ was noted in chronic group. Regarding RBCs, a significant decline was shown in acute group $(P=0.0009)$ on the contrary to chronic group which showed a rise of $11 \%$ compared to the control $(P=\mathbf{0 . 0 0 7 3})$.

agents has induced chronic inflammation which is usually associated with cancer development [55,56]. $80 \mathrm{mg}$ Earthworm paste/kg treated rat showed same trend of WBC, RBC and Hb contents [57]. Falling in line with these observations it was found that in the present study, $200 \mathrm{mg} / \mathrm{L}$ of TAA treated group showed reduction of 45\% in WBCs (Leucopenia) and increase of 11 and 4.1\% of RBC and Hb contents, respectively (polycythemia). A transient increase of RBC and $\mathrm{Hb}$ contents were Registered together lymphopenia in rats intramuscularly injected with $5 \mathrm{ml} / \mathrm{kg}$ of Nerium oleander aqueous leaf extract (unpublished data). Chronic group in this study showed similar results and are in accordance with previous data.
Neutrophils and its derived cytokines play a crucial role in the development and manifestation of inflammation. The stimulation of neutrophils can lead to the production of oxygen-derived free radicals also called reactive oxygen species (ROS) that cause further cellular damage [58]. The formation of free radicals and cytotoxic oxygen metabolites probably impart a key role in various types of tissue degeneration and pathology such as aging, cancer and retinal degeneration [33,55,59]. In the present study, after intraperitonial injection of TAA, significant elevation in the neutrophil count (neutrophilia) occurs with $283 \%$ rise in its level compared to control was may be due to the free radicals resulting from TAA metabolism which caused liver injury and a proportion of 
these free radicals librated into the blood may also affect the circulating cells and induced a significant change in their number. This significant neutrophilia might reflects its involvement in inflammation by forming various reactive oxygen species (ROS), inflammatory, metabolic and myloproliferative disorders, tissue necrosis, acute hemorrhagia, malignant tumors or due to rapid release of young cells from the bone marrow [60]. Similarly, in previous reports, significant neutrophilia, and decrease of circulating lymphocytes, remaining below control levels after $4 \mathrm{~h}$ was observed with intramuscular turpentine oil treatment of rats [61]. This notion was indicated by the acute group in this study and in accordance with previous data [62].

\section{Conclusion}

Taken together these findings we can conclude that the animals respond differently under acute and chronic inflammatory condition with TAA administration. Leukocytosis with marked neutrophilia, thrombocytosis as well as increased hemoglobin concentration and decline of erythrocytic count were observed in acute while leucopenia accompanied with neutropenia and thrombocytopenia and increase in RBCs, $\mathrm{Hb}$ and Hct was also observed with a decline of other red cell indices during chronic phase.

\section{Author's Contributions}

Muddasir Hassan Abbasi involved in the experimental work, data analysis and manuscript draft.

Tasleem Akhtar involved in the chronic treatment experimental work, data collection and manuscript draft.

Ihtzaz A. Malik participated in the study design.

Sana Fatima participated in interpretation of results.

Babar Khawarand Ghulam Mustafa involved in acute treatment experimental work.

Khawaja Abdul Mujeeb and Javaid Iqbal involved in trouble shooting suggestions and discussion for acute experiments.

Shabir Hussain performed hematology.

Nadeem Sheikh provided the concept, participated in the design of study, supervised the manuscript draft and approved the final manuscript.

\section{Acknowledgements}

The authors are thankful to the Vice Chancellor, University of the Punjab, Lahore, Pakistan for providing financial support to publish the article.

\section{REFERENCES}

[1] J. Chilakapati, K. Shankar, M. C. Korrapati, R. A. Hill and H. M. Mehendale, "Saturation Toxicokinetics of
Thioacetamide: Role in Initiation of Liver Injury,” Drug Metabolism and Disposition, Vol. 33, No. 12, 2005, pp. 1877-1885.

[2] J. F. Childs and E. A. Siegler, "Compound for Control of Orange Decays,” Science, Vol. 102, No. 2538, 1945, pp. 68-69. doi:10.1126/science.102.2638.68

[3] O. G. Fitzhugh and A. A. Nelson, "Liver Tumors in Rats Fed Thiourea or Thioacetamide,” Science, Vol. 108, No. 2814, 1948, pp. 626-628. doi:10.1126/science.108.2814.626

[4] J. W. Lee, K. D. Shin, M. Lee, E. J. Kim, S. S. Han, M. Y. Han, et al., "Role of Metabolism by Flavin-Containing Monooxygenase in Thioacetamide-Induced Immunosuppression,” Toxicology Letters, Vol. 136, No. 3, 2003, pp. 163-172. doi:10.1016/S0378-4274(02)00333-8

[5] J. M. Yang, D. W. Han, C. M. Xie, Q. C. Liang, Y. C. Zhao and X. H. Ma, "Endotoxins Enhance Hepatocarcinogenesis Induced by Oral Intake of Thioacetamide in Rats,” World Journal of Gastroenterology, Vol. 4, No. 2, 1998, pp. 128-132.

[6] S. Chanda and M. Mehendale, "Role of Nutritional Fatty Acid and L-Carnitine in the Final Outcome of Thioacetamide Hepatotoxicity," The FASEB Journal, Vol. 8, No. 13, 1994, pp. 1061-1068.

[7] W. R. Porter, M. J. Gudzinowicz and R. A. Neal, "Thioacetamide-Induced Hepatic Necrosis. II. Pharmacokinetics of Thioacetamide and Thioacetamide-S-Oxide in the Rat," Journal of Pharmacology and Experimental Therapeutics, Vol. 208, No. 3, 1979, pp. 386-391.

[8] A. al-Bader, T. C. Mathew, M. Khoursheed, S. Asfar, H. al-Sayer and H. M. Dashti, "Thioacetamide Toxicity and the Spleen: Histological and Biochemical Analysis," Anatomia, Histologia, Embryologia, Vol. 29, No. 1, 2000, pp. 3-8. doi:10.1046/j.1439-0264.2000.00207.x

[9] E. A. Barker and E. A. Smuckler, "Nonhepatic Thioacetamide Injury. II. The Morphologic Features of Proximal Renal Tubular Injury,” American Journal of Pathology, Vol. 74, No. 3, 1974, pp. 575-590.

[10] S. M. Latha, M. R. Pai and P. K. Pai, "Thioacetamide Toxicity and the Lung: Histological Analysis," Indian Journal of Physiology and Pharmacology, Vol. 47, No. 4, 2003, pp. 476-478.

[11] M. A. Ortega, M. I. Torres, M. I. Fernandez, A. Rios, A. Sanchez-Pozo and A. Gil, "Hepatotoxic Agent Thioacetamide Induces Biochemical and Histological Alterations in Rat Small Intestine,” Digestive Diseases and Sciences, Vol. 42, No. 8, 1997, pp. 1715-1723. doi:10.1023/A:1018817600238

[12] A. A. Al-Bader, T. C. Mathew, H. Abul, M. Al-Mosawi, H. M. Dashti, D. Kumar, et al., “Thioacetamide Induced Changes in Trace Elements and Kidney Damage," The Journal of Trace Elements in Experimental Medicine, Vol. 12, No. 1, 1999, pp. 1-14. doi:10.1002/(SICI)1520-670X(1999)12:1<1::AID-JTRA1 $>3.0 . \mathrm{CO} ; 2-\mathrm{L}$

[13] E. A. Barker and E. A. Smuckler, "Altered Microsome Function during Acute Thioacetamide Poisoning," Molecular Pharmacology, Vol. 8, No. 3, 1972, pp. 318-326. 
[14] E. Chieli and G. Malvaldi, "Role of the Microsomal FadContaining Monooxygenase in the Liver Toxicity of Thioacetamide S-Oxide,” Toxicology, Vol. 31, No. 1, 1984, pp. 41-52. doi:10.1016/0300-483X(84)90154-9

[15] T. Y. Low, C. K. Leow, M. Salto-Tellez and M. C. Chung, "A Proteomic Analysis of Thioacetamide-Induced Hepatotoxicity and Cirrhosis in Rat Livers," Proteomics, Vol. 4, No. 12, 2004, pp. 3960-3974. doi:10.1002/pmic.200400852

[16] K. H. Kim, J. H. Bae, S. W. Cha, S. S. Han, K. H. Park and T. C. Jeong, "Role of Metabolic Activation by Cytochrome P450 in Thioacetamide-Induced Suppression of Antibody Response in Male BALB/c Mice,” Toxicology Letters, Vol. 114, No. 1-3, 2000, pp. 225-235. doi:10.1016/S0378-4274(00)00168-5

[17] N. Sanz, F. C. Diez, S. L. Fernandez, A. Alvarez and M. Cascales, "Necrogenic and Regenerative Responses of Liver of Newly Weaned Rats against a Sublethal Dose of Thioacetamide,” Biochimica et Biophysica Acta (BBA)Protein Structure and Molecular Enzymology, Vol. 1384, No. 1, 1998, pp. 66-78. doi:10.1016/S0167-4838(97)00218-5

[18] A. Zaragoza, D. Andrs, D. Sarrin and M. Cascales, "Potentiation of Thioacetamide Hepatotoxicity by Phenobarbital Pretreatment in Rats. Inducibility of FAD Monooxygenase System and Age Effect," Chemico-Biological Interactions, Vol. 124, No. 2, 2000, pp. 87-101. doi:10.1016/S0009-2797(99)00147-7

[19] F. Sun, S. Hayami, Y. Ogiri, S. Haruna, K. Tanaka, Y. Yamada, et al., "Evaluation of Oxidative Stress Based on Lipid Hydroperoxide, Vitamin C and Vitamin E during Apoptosis and Necrosis Caused by Thioacetamide in Rat Liver," Biochimica et Biophysica Acta (BBA)—Molecular Basis of Disease, Vol. 1500, No. 2, 2000, pp. 181-185. doi:10.1016/S0925-4439(99)00100-3

[20] N. J. Waters, C. J. Waterfield, R. D. Farrant, E. Holmes and J. K. Nicholson, "Metabonomic Deconvolution Of Embedded Toxicity: Application to Thioacetamide Hepato- and Nephrotoxicity," Chemical Research in Toxicology, Vol. 18, No. 4, 2005, pp. 639-654. doi:10.1021/tx049869b

[21] M. E. Caballero, J. Berlanga, D. Ramirez, P. Lopez-Saura, R. Gozalez, D. N. Floyd, et al., "Epidermal Growth Factor Reduces Multiorgan Failure Induced by Thioacetamide,” Gut, Vol. 48, No. 1, 2001, pp. 34-40. doi:10.1136/gut.48.1.34

[22] P. David, E. Alexandre, M. P. Chenard-Neu, P. Wolf, D. Jaeck and L. Richert, "Failure of Liver Cirrhosis Induction by Thioacetamide in Nagase Analbuminaemic Rats," Laboratory Animals, Vol. 36, No. 2, 2002, pp. 158-164. doi:10.1258/0023677021912442

[23] A. Watanabe, M. A. Sohail, D. A. Gomes, A. Hashmi, J. Nagata, F. S. Sutterwala, S. Mahmood, M. N. Jhandier, Y. Shi, R. A. Flavell and W. Z. Mehal, "Inflammasomemediated Regulation of Hepatic Stellate Cells," American Journal of Physiology-Gastrointestinal and Liver Physiology, Vol. 296, No. 6, 2009, pp. G1248-G1257. doi:10.1152/ajpgi.90223.2008

[24] S. K. Ramaiah, U. Apte and H. M. Mehendale, “Cyto- chrome P4502E1 Induction Increases Thioacetamide Liver Injury in Diet-Restricted Rats,” Drug Metabolism and Disposition, Vol. 29, No. 8, 2001, pp. 1088-1095.

[25] P. H. Rondo, A. Conde, M. C. Souza and A. Sakuma, "Iron Deficiency Anaemia and Blood Lead Concentrations in Brazilian Children," Transactions of the Royal Society of Tropical Medicine and Hygiene, Vol. 105, No. 9, 2011, pp. 525-530. doi:10.1016/j.trstmh.2011.05.012

[26] M. Mulas, B. Perinu and A. H. D. Francesconi, "Evaluation of Spontaneous Oleander (Nerium oleander L.) as a Medicinal Plant,” Journal of Herbs, Spices \& Medicinal Plants, Vol. 9, No. 2-3, 2002, pp. 121-125. doi:10.1300/J044v09n02_17

[27] P. M. Huet, L. Giroux, M. Laurens and D. Crenesse, "Effect of Cold Ischemia Warm Reperfusion on the Cirrhotic Rat Liver," Liver Transplantation, Vol. 14, No. 4, 2008, pp. 486-493. doi:10.1002/lt.21392

[28] T. Matsuhashi, M. Otaka, M. Odashima, M. Jin, K. Komatsu, N. Konishi, I. Wada, T. Sato, Y. Horikawa, R. Ohba, J. Oyake, N. Hatakeyama and S. Watanabe, "Specific Type IV Phosphodiesterase Inhibitor Ameliorates Thioacetamide-Induced Liver Injury in Rats," Journal of Gastroenterology and Hepatology, Vol. 20, No. 1, 2005, pp. 135-140. doi:10.1111/j.1440-1746.2004.03512.x

[29] V. Gayathri, S. Ananthi, C. Chandronitha, G. Ramakrishnan, R. L. Sundaram and H. R. Vasanthi, "Cardioprotective Effect of Nerium Oleander Flower Against Isoproterenol-Induced Myocardial Oxidative Stress in Experimental Rats," Journal of Cardiovascular Pharmacology and Therapeutics, Vol. 16, No. 1, 2011, pp. 96-104. doi:10.1177/1074248410381759

[30] J. S. Kang, H. Wanibuchi, K. Morimura, R. Puatanachokchai, E. I. Salim, A. Hagihara, et al., "Enhancement by Estradiol 3-Benzoate in Thioacetamide-Induced Liver Cirrhosis of Rats,” Toxicological Sciences, Vol. 85, No. 1, 2005, pp. 720-726. doi:10.1093/toxsci/kfi113

[31] M. A. Constantinou, S. E. Theocharis and E. Mikros, "Application of Metabonomics on an Experimental Model of Fibrosis and Cirrhosis Induced by Thioacetamide in Rats," Toxicology and Applied Pharmacology, Vol. 218, No. 1, 2007, pp. 11-19. doi:10.1016/j.taap.2006.10.007

[32] C. N. Yeh, A. Maitra, K. F. Lee, Y. Y. Jan and M. F. Chen, "Thioacetamide-Induced Intestinal-Type Cholangiocarcinoma in Rat: An Animal Model Recapitulating the Multi-Stage Progression of Human Cholangiocarcinoma,” Carcinogenesis, Vol. 25, No. 4, 2004, pp. 631636. doi:10.1093/carcin/bgh037

[33] H. Shapiro, M. Ashkenazi, N. Weizman, M. Shahmurov, H. Aeed and R. Bruck, "Curcumin Ameliorates Acute Thioacetamide-Induced Hepatotoxicity,” Journal of Gastroenterology and Hepatology, Vol. 21, No. 2, 2006, pp. 358-366. doi:10.1111/j.1440-1746.2005.03984.x

[34] N. K. Gupta and V. K. Dixit, "Hepatoprotective Activity of Cleome Viscosa Linn. Extract against ThioacetamideInduced Hepatotoxicity in Rats," Natural Product Research, Vol. 23, No. 14, 2009, pp. 1289-1297. doi:10.1080/14786410802447302

[35] J. H. An, J. Seong, H. Oh, W. Kim, K. H. Han and Y. H. Paik, "Protein Expression Profiles in a Rat Cirrhotic Mo- 
del Induced by Thioacetamide,” Korean Journal of Hepatology, Vol. 12, No. 1, 2006, pp. 93-102.

[36] X. Li, I. S. Benjamin and B. Alexander, "Reproducible Production of Thioacetamide-Induced Macronodular Cirrhosis in the Rat with No Mortality," Journal of Hepatology, Vol. 36, No. 4, 2002, pp. 488-493. doi:10.1016/S0168-8278(02)00011-9

[37] M. J. Perez, A. Suarez, J. A. Gomez-Capilla, F. Sanchez-Medina and A. Gil, "Dietary Nucleotide Supplementation Reduces Thioacetamide-Induced Liver Fibrosis in Rats,” The Journal of Nutrition, Vol. 132, No. 4, 2002, pp. 652-657.

[38] T. M. Rahman and H. J. F. Hodgson, "The Effects of Early and Late Administration of Inhibitors of inducible Nitric Oxide Synthase in a Thioacetamide-Induced Model of Acute Hepatic Failure in the Rat," Journal of Hepatology, Vol. 38, No. 5, 2003, pp. 583-590. doi:10.1016/S0168-8278(03)00050-3

[39] T. M. Rahman and H. J. Hodgson, “Animal Models of Acute Hepatic Failure,” International Journal of Experimental Pathology, Vol. 81, No. 2, 2000, pp. 145-157. doi:10.1046/j.1365-2613.2000.00144.x

[40] M. Belanger and R. Butterworth, "Acute Liver Failure: A Critical Appraisal of Available Animal Models," Metabolic Brain Disease, Vol. 20, No. 4, 2005, pp. 409-423. doi:10.1007/s11011-005-7927-z

[41] P. Stankova, O. Kucera, H. Lotkova, T. Rousar, R. Endlicher and Z. Cervinkova, "The Toxic Effect of Thioacetamide on Rat Liver in Vitro," Toxicology in Vitro, Vol. 24, No. 8, 2010, pp. 2097-2103. doi:10.1016/j.tiv.2010.06.011

[42] T. M. Chen, Y. M. Subeq, R. P. Lee, T. W. Chiou and B. G. Hsu, "Single Dose Intravenous Thioacetamide Administration as a Model of Acute Liver Damage in Rats," International Journal of Experimental Pathology, Vol. 89, No. 4, 2008, pp. 223-231. doi:10.1111/j.1365-2613.2008.00576.x

[43] M. I. Torres, M.I. Fernández, A. Gil and A. Ríos, "Dietary Nucleotides Have Cytoprotective Properties in Rat Liver Damaged by Thioacetamide," Life Sciences, Vol. 62, No. 1, 1997, pp. 13-22. doi:10.1016/S0024-3205(97)01033-3

[44] S. K. Natarajan, S. Thomas, P. Ramamoorthy, J. Basivireddy, A. B. Pulimood, A. Ramachandran, et al., "Oxidative Stress in the Development of Liver Cirrhosis: A Comparison of Two Different Experimental Models," Journal of Gastroenterology and Hepatology, Vol. 21, No. 6, 2006, pp. 947-957. doi:10.1111/j.1440-1746.2006.04231.x

[45] W. Olipitz, D. Strunk, C. Beham-Schmid and H. Sill, "Neutrophilic Leukemoid Reaction as the Presenting Feature of de Novo and Therapy-Related Acute Leukemias,” Acta Haematologica, Vol. 111, No. 4, 2004, pp. 233-234. doi:10.1159/000077574

[46] A. Ballinger, "Gastroenterology and Anaemia," Medicine, Vol. 35, No. 3, 2007, pp. 142-146.

[47] O. M. P. Jolobe, "Prevalence of Hypochromia (without Microcytosis) vs Microcytosis (without Hypochromia) in Iron Deficiency,” Clinical \& Laboratory Haematology,
Vol. 22, No. 2, 2000, pp. 79-80. doi:10.1046/j.1365-2257.2000.00293.x

[48] G. S. Travlos, R. W. Morris, M. R. Elwell, A. Duke, S. Rosenblum and M. B. Thompson, "Frequency and Relationships of Clinical Chemistry and Liver and Kidney Histopathology Findings in 13-Week Toxicity Studies in Rats,” Toxicology, Vol. 107, No. 1, 1996, pp. 17-29. doi:10.1016/0300-483X(95)03197-N

[49] D. W. Kaufman, J. P. Kelly, C. B. Johannes, A. Sandler, D. Harmon, P. D. Stolley, et al., "Acute Thrombocytopenic Purpura in Relation to the Use of Drugs," Blood, Vol. 82, No. 9, 1993, pp. 2714-2718.

[50] J. N. George, G. E. Raskob, S. R. Shah, M. A. Rizvi, S. A. Hamilton, S. Osborne, et al., "Drug-Induced Thrombocytopenia: A Systematic Review of Published Case Reports," Annals of Internal Medicine, Vol. 129, No. 11, 1998, pp. 886-890.

[51] D. B. Cines, J. B. Bussel, H. A. Liebman and E. T. Luning Prak, "The ITP Syndrome: Pathogenic and Clinical diversity,” Blood, Vol. 113, No. 26, 2009, pp. 6511-6521. doi:10.1182/blood-2009-01-129155

[52] D. Nantakomol, A. Palasuwan, M. Chaowanathikhom, S. Soogarun and M. Imwong, "Red Cell and Platelet Derived Microparticles Are Increased in g6pd Deficient Subjects,” European Journal of Haematology, Vol. 89, No. 5, 2012, pp. 423-429.

[53] S. Fatma, O. Batu, E. Yildirim, K. Erol, S. Deliorman, et al., "Ciprofloxacin and Pefloxacin Suppress the Inflammatory Response in Rats," Journal of Health Science, Vol. 49, No. 5, 2003, pp. 391-394. doi:10.1248/jhs.49.391

[54] A. C. A. Moura, E. L. F. Silva, M. C. A. Fraga, A. G. Wanderley, P. Afiatpour and M. B. S. Maia, "Antiinflammatory and Chronic Toxicity Study of the Leaves of Ageratum Conyzoides L. in Rats,” Phytomedicine, Vol. 12, No. 1-2, 2005, pp. 138-142. doi:10.1016/j.phymed.2003.12.003

[55] S. P. Hussain and C. C. Harris, "Inflammation and Cancer: An Ancient Link with Novel Potentials," International Journal of Cancer, Vol. 121, No. 1-2, 2007, pp. 23732380. doi:10.1002/ijc.23173

[56] H. Lu, W. Ouyang and C. Huang, "Inflammation, a Key Event in Cancer Development," Molecular Cancer Research, Vol. 4, No. 4, 2006, pp. 221-233. doi:10.1158/1541-7786.MCR-05-0261

[57] M. Balamurugan, K. Parthasarathi, E. L. Cooper and L. S. Ranganathan, "Earthworm Paste (Lampito mauritii, Kinberg) Alters Inflammatory, Oxidative, Haematological and Serum Biochemical Indices of Inflamed Rat,” European Review for Medical and Pharmacological Sciences, Vol. 11, No. 2, 2007, pp. 77-90.

[58] G. Bartosz, "Free Radicals in Biology and Medicine," Cell Biology International, Vol. 24, No. 10, 2000, p. 764. doi:10.1006/cbir.1999.0607

[59] A. Z. Reznick, N. Shehadeh, Y. Shafir and R. M. Nagler, "Free Radicals Related Effects and Antioxidants in Saliva and Serum of Adolescents with Type 1 Diabetes Mellitus,” Archives of Oral Biology, Vol. 51, No. 8, 2006, pp. 640-648. doi:10.1016/j.archoralbio.2006.02.004 
[60] K. Doi, S. Kurabe, N. Shimazu and M. Inagaki, "Systemic Histopathology of Rats with CCl4-Induced Hepatic Cirrhosis,” Laboratory Animals, Vol. 25, No. 1, 1991, pp. 21-25. doi:10.1258/002367791780808121

[61] N. Sheikh, K. Tron, J. Dudas and G. Ramadori, “Cytokine-Induced Neutrophil Chemoattractant-1 is Released by the Noninjured Liver in a Rat Acute-Phase Model,"

\section{List of Abbreviations:}

B.W. Body weight

FMOs Flavin-containing monooxygenase

$\mathrm{Hb}$ Haemoglobin

Hct Hematocrite

$\mathrm{MCH}$ Mean cell hemoglobin

MCHC Mean cell hemoglobin concentration

MCV Mean cell volume
Laboratory Investigation, Vol. 86, No. 8, 2006, pp. 800814.

[62] M. I. Al-Farwachi, M. S. Rhaymah and B. A. Al-Badrani, "Acute Toxicity of Nerium Oleander Aqueous Leaf Extract in Rabbits," Iraqi Journal of Veterinary Sciences, Vol. 22, No. 1, 2008, pp. 1-4.

TAA Thioacetamide

TLC Total leukocyte count

TASO Thioacetamide-S-oxide

Plts Platelets

RBCs Red blood cells

ROS Reactive oxygen species

WBCs White blood cells 